\title{
Osteological Development of the Larvae and Juvenile of Bullhead torrent catfish, Liobagrus obesus
}

\author{
Won-Il Seo ${ }^{1}$, Jae-Min Park², Sung-Hun Lee ${ }^{3}$, Seong Min Yoon ${ }^{4}$, \\ Seon-Yeong Hwang ${ }^{1}$, and Kyeong-Ho Han ${ }^{3}$ \\ ${ }^{1}$ Jeollanam-Do Ocean and Fisherises Science Institute, Yeosu 59713, Korea \\ ${ }^{2}$ Gyeongsangbuk-Do Native Fish Business Center, Uiseong 37366, Korea \\ ${ }^{3}$ Marine Technology Undergraduate, Chonnam National University, Yeosu 59626, Korea \\ ${ }^{4}$ Gyeongsangbuk-Do Research Center for Freshwater Fishes, Uljin 36332, Korea
}

\begin{abstract}
This study was conducted to investigate the skeletal development of bullhead torrent catfish, $L i$ obagrus obesus larvae and to utilize them as basic data for the taxonomic study of Liobagrus larvae. Skeletal development was observed by being divided into cranium, visceral skeleton, shoulder girdle bone, pelvic girdle bone and vertebra. On the first day after hatching, the pre-larvae had an average total length of $7.92 \mathrm{~mm}$, and a line-shaped parasphenoid ossified in the cranium. In the jaw bone, the dentary supporting the lower jaw and the maxillary supporting the upper jaw were ossified. In the anterior abdominal vertebrae of the vertebra, seven centrums began to ossify and five neural spines ossified simultaneously. On the 3 day after hatching, pre-larvae had an average total length of $8.95 \mathrm{~mm}$, and the prefrontal ossified in cranium. The number of abdominal vertebrae was increased to 14 , and three parapophysis developed from the front side. On the 24th day after hatching, postlarvae had an average total length of $15.2 \mathrm{~mm}$ and the epural bone ossified in coccyx. The parhypural bone was ossified, and ossification of coccyx and pelvic girdle bone was completed. On the 30th day after hatching, the average total length of the juvenile was $17.8 \mathrm{~mm}$, and the ossification of cranium and visceral skeleton was all completed while the preorbital and three suborbitals were ossified in the orbital region of the cranium.
\end{abstract}

Key words : Bullhead torrent catfish, Juvenile, Larvae, Liobagrus obesus, Osteological

\section{INTRODUCTION}

Liobagrus obesus is a fish belonging to Siluriformes Amblycipitidae Liobagrus, and it is known to be distributed in the Geumgang River and the Ungcheon River, Mangyeong River and upper stream of Yeongsan River. Amblycipitidae fish are commonly characterized by four pairs of barbells and a thorn on the pectoral fin, and there are three species known in Korea including L. andersoni and $L$. mediadiposalis as well as L. obesus (Kim et al., 2005).

L. obesus and L. andersoni have been in confusion due to their similarities in shape, but through taxonomic studies, these are divided by the number of pectoral fins and the number of chromosomes according to the distribution

\footnotetext{
Manuscript received January 29, Received in revised form March 3, 2018, Accepted March 14, 2018

${ }^{\dagger}$ Corresponding Author : Kyeong Ho Han, Marine Technology Undergraduate, Chonnam National University, Yeosu 59626, Korea. Tel: +82-61-6597163, Fax: +82-61-659-7169, E-mail: aqua05@jnu.ac.kr

This is an Open Access article distributed under the terms of the Creative Commons Attribution Non-Commercial License (http:// creative-commons.org/licenses/by-nc/3.0) which permits unrestricted non-commercial use, distribution, and reproduction in any medium, provided the original work is properly cited.
} 
area (Son \& Lee, 1989). In addition, L. obesus is a species native to Korea and has very limited habitats and fewer populations, and is designated and protected by the Ministry of Environment in 1998 as an endangered species of wild fauna and flora (NBC, 2018).

Studies of Liobagrus include the early life history (Seo et al., 2006), spawning behavior and early life history of $L$. mediadiposalis (Choi et al., 2008), feeding habits of $L$. obesus (Son \& Byeon, 2004), characteristics of natural spawning ground (Kim et al., 2012), feeding habits of $L$. andersoni (Yoon et al., 2007), metrological trait characteristic (Park et al., 2006) and karyotype analysis (Son \& Lee, 1989), etc. However, there has been no study of skeletal development for taxonomic studies.

Studies on the skeletal development of fishes are important for the identification of species as well as skeletal characteristics of fishes, so detailed and systematic studies are needed (Koumoundouros et al., 1997a,b). Also, the stage of morphogenesis of the adolescent period helps to understand the systematic basic trait expression, functional development tendency and preference for the environment, and research in this field is diverse (Mook, 1977; Potthoff et al., 1988; Fukuhara, 1992; Faustino \& Power, 1999; Koumoundouros et al., 1999; Liu, 2001; Sfakianakis et al., 2004).

In particular, three species of Liobagrus fish have been attracting attention as an important research area due to regional differences in form. So far, the research on the internal skeleton of Liobagrus fish has been lacking, and this study examines larvae skeletal development of $L$. obesus to use the results as a basic data for taxonomic research and artificial proliferation.

\section{MATERIALS AND METHODS}

\section{Obtaining fertilized eggs}

The brood stork fish used in this study were secured during the research on the preservation, restoration and propagation technology development of the endangered species of Korean specialty fish, which is the next generation core environment technology development project of Ministry of Environment (Project No. 652-041-006), and the research was conducted in May 2004, in the Chogangcheon Stream located in Yeongdong-gun, Chungnam Province. The embryos of $L$. obesus were collected under the rocks where the flow speed was relatively gentle. Collected embryos were transferred to the laboratory and housed in a rectangular glass water bath $(35 \times 50 \times 30 \mathrm{~cm})$. The water temperature was maintained at $19.5-24.9^{\circ} \mathrm{C}$ (average $22.2 \pm 3.81^{\circ} \mathrm{C}$ ) by using a sponge filter.

\section{Larvae breeding and skeletal dyeing}

Larvae were kept in a circulatory system in the fertilized egg management tank. The temperature of the rearing water remained the same as the embryos. Feeding of Artemia sp. nauplius larvae supplied at 5-10 per $\mathrm{mL}$ was carried out from the $10^{\text {th }}$ day to the 16 th day after hatching and absorbing egg yolk. Sludge worms were supplied from $16^{\text {th }}$ to $24^{\text {th }}$ day after hatching. From $24^{\text {th }}$ day after hatching, frozen blood worms were supplied. For skeletal developmental observation, five individuals were collected every day from immediately after hatching and fixed to $10 \%$ neutral formalin. Skeletal staining was performed by double staining of Kawamura \& Hosoya (1991). The stained larvae were stored in 50\% Glycerin. Sections of each skeleton were sketched using a universal projector (Nikon JP V-12B, Japan) and a stereomicroscope (Nikon NM-40, Japan) to sketch the developmental process. The names of each site followed Kang et al. (2012) and Park et al. (2015).

\section{RESULTS}

\section{Larvae skeletal development}

For observation of skeletal development of $L$. obesus larvae, it was divided into cranium, visceral skeleton, shoulder girdle bone, pelvic girdle bone and vertebra. 
1) Cranium and visceral skeleton

The development of cranium and visceral skeleton of $L$. obesus larvae is shown in Table 1 . Shortly after hatching, the pre-larvae showed a linear parasphenoid ossification in the cranium with an overall length of 7.52-7.69 (mean $7.60 \pm 0.12) \mathrm{mm}$. In the jaw bone, the dentary supporting the lower jaw and the maxillary supporting the upper jaw were ossified (Fig. 1A).

Table 1. The ossification process of cranium and visceral skeleton in Liobagrus obesus

\begin{tabular}{|c|c|c|c|c|c|c|c|}
\hline & \multirow{2}{*}{ Elements } & \multicolumn{6}{|c|}{ Total length (mm) } \\
\hline & & 7.60 & 8.95 & 9.62 & 13.4 & 15.2 & 17.7 \\
\hline \multirow[t]{10}{*}{ Cranium } & Parasphenoid & & & & & & \\
\hline & Prefrontal & & & & & & \\
\hline & Pterotic & & & & & & \\
\hline & Frontal & & & & & & \\
\hline & Basioccipital & & & & & & \\
\hline & Epiotic & & & & & & \\
\hline & Exoccipital & & & & & & \\
\hline & Nasal & & & & & & \\
\hline & Vomer & & & & & & \\
\hline & Ethmoid & & & & & & \\
\hline \multirow[t]{3}{*}{ Upper jaw } & Maxillary & & & & & & \\
\hline & Premaxillary & & & & & & \\
\hline & Supramaxillary & & & & & & \\
\hline \multirow[t]{2}{*}{ Lower jaw } & Dentary & & & & & & \\
\hline & Articular & & & & & & \\
\hline \multirow[t]{3}{*}{ Hyoid arch } & Ceratohyal & & & & & & \\
\hline & Epihyal & & & & & & \\
\hline & Hypohyal & & & & & & \\
\hline \multirow[t]{5}{*}{ Palate } & Hyomandibular & & & & & & \\
\hline & Qudrate & & & & & & \\
\hline & Ectopterygoid & & & & & & \\
\hline & Endopterygoid & & & & & & \\
\hline & Symplectic & & & & & & \\
\hline \multirow[t]{4}{*}{ Opercular } & Opercle & & & & & & \\
\hline & Preopercle & & & & & & \\
\hline & Interopercle & & & & & & \\
\hline & Subopercle & & & & & & \\
\hline \multirow[t]{2}{*}{ Orbital region } & Preorbital & & & & & & \\
\hline & Suborbital & & & & & & \\
\hline
\end{tabular}



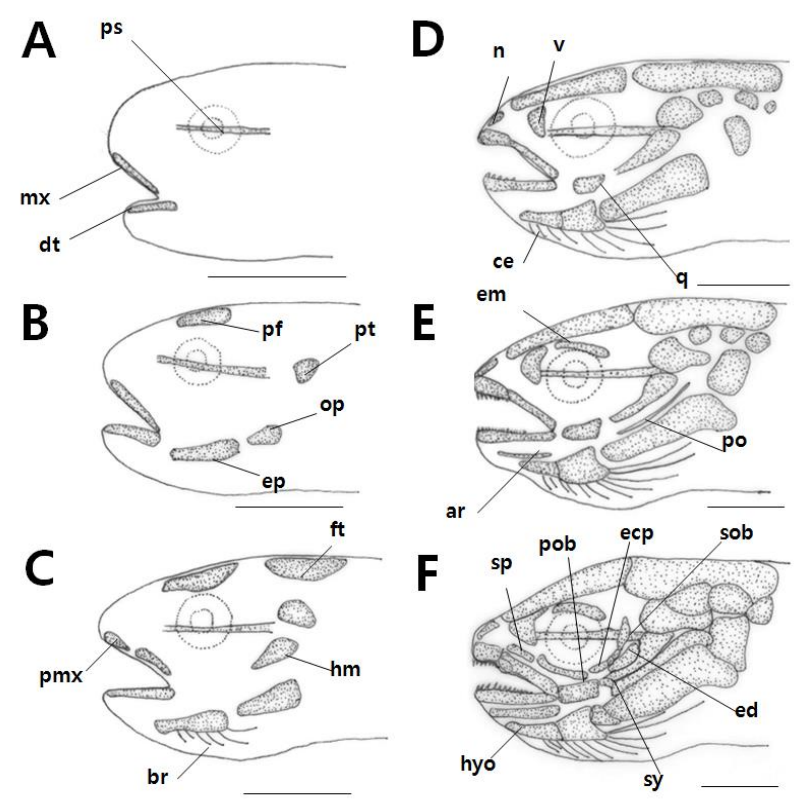

Fig. 1. Ossification of the cranium and visceral skeleton in Liobagrus obesus. A: $7.60 \mathrm{~mm}$ in total length (TL) newly hatched larvae; B: $8.95 \mathrm{~mm}$ in TL 3 days after hatching; C: $9.62 \mathrm{~mm}$ in TL, 10 days after hatching; D: $13.4 \mathrm{~mm}$ in TL 16 days after hatching; E: $15.2 \mathrm{~mm}$ in TL 24 days after hatching; F: $17.7 \mathrm{~mm}$ in TL 30 days after hatching. ar, articular; br, branchiostegals; ce, ceratohyal; dt, dentary; ecp, ectopterygoid; ed, endopterygoid; ep, epihyal; em, ethmoid; ft, frontal; hm, hyomadibular; hyo, hypohyal; mx, maxillary; n, nasal; op, opercle; po, preopercle; pf, prefrontal; pob, preorbital; pt, pterotic; pmx, premaxillary; ps, parasphenoid; q, quadrate; sp, sphenotic; sob, suborbital; sy, sympletic; v, vomer. Scale bars $=0.5 \mathrm{~mm}$.

On the 3 day after hatching, Pre-larvae had an average total length of 8.92 to 8.99 (mean $8.95 \pm 0.04$ ) $\mathrm{mm}$, and prefrontal ossification in the cranium. Pterotic ossification was observed behind the parasphenoid, epihyal ossified in the hyoid arches of the visceral skeleton, and opercle ossified in the operculum (Fig. 1B).

On the 10th day after hatching, prelarvae were 9.24-10.0 (mean $9.62 \pm 0.53$ ) $\mathrm{mm}$ in total length and hyomandibular ossified in palate. The frontal ossified in the cranium, and six branchiostegal rays ossified in the hyoid arches. In the jaw bone, the premaxillary was ossified above the maxillary (Fig. 1C).

At 16 days after hatching, posterior larvae were 13.4$13.5 \mathrm{~mm}$ in total length (mean $13.4 \pm 0.07 \mathrm{~mm}$ ), and the vomer, nasal, epiotic, exoccipital, posttemporal and basioccipital were ossified in the cranium and the quadrate was ossified in the palate. In hyoid arches, ceratohyal bone was ossified, and branchiostegal rays increased to 9 (Fig. 1D).

At 24 days after hatching, post-larvae were 15.2-15.3 $\mathrm{mm}$ in total length (mean $15.2 \pm 0.07 \mathrm{~mm}$ ), and the ethmoid was ossified in the cranium. Supramaxillary and articular ossified in the jaw bone, and preopercle ossified in the operculum (Fig. 1E).

At 30 days after hatching, juvenile was $17.7-17.8 \mathrm{~mm}$ in total length (mean $17.8 \pm 0.07 \mathrm{~mm}$ ). The preorbital and three suborbitals were ossified in the cranium orbital region and the endopterygoid and ectopterygoid were ossified. The ossification of cranium and visceral skeleton was all completed with hypohyal ossification in the operculum (Fig. 1F).

\section{2) Vertebra, coccyx and pelvic girdle bone}

Table 2 shows the development of the vertebra, coccyx and pelvic girdle bones of $L$. obesus larvae. Immediately after hatching, the pre-larvae were $7.60 \pm 0.12 \mathrm{~mm}$ in mean length and seven centrums in the anterior abdominal vertebrae of the vertebra began to ossify. Five neural spines were simultaneously ossified (Fig. 2A).

On the 3 day after hatching, the mean length of prelarvae was $8.95 \pm 0.04 \mathrm{~mm}$, and the number of abdominal vertebrae increased to 14 . Three parapophysis developed from the front. 24 caudal vertebrae were ossified, and the number of vertebra was $14+24=38$. Neural spines were increased to 24, and four hemal spines ossified (Fig. 2B).

On the 10th day after hatching, pre-larvae were $9.62 \pm$ $0.53 \mathrm{~mm}$ in total length and the caudal vertebrae were increased to 28 and the number of vertebra was $14+28=42$ to complete ossification. The number of parapophysis was increased to 5 , and 7 interneural spines and 5 interhemal 
Table 2. The ossification process of vertebra and caudal skeleton and shoulder girdle bone in Liobagrus obesus

\begin{tabular}{|c|c|c|c|c|c|c|c|}
\hline & \multirow{2}{*}{ Elements } & \multicolumn{6}{|c|}{ Total length (mm) } \\
\hline & & 7.60 & 8.95 & 9.62 & 13.4 & 15.2 & 17.7 \\
\hline \multirow[t]{8}{*}{ Vertebra } & Neural spine & & & & & & \\
\hline & Abdominal vertebra & & & & & & \\
\hline & Hemal spine & & & & & & \\
\hline & Caudal vertebra & & & & & & \\
\hline & Interneural spine & & & & & & \\
\hline & Interhemal spine & & & & & & \\
\hline & Parapophysis & & & & & & \\
\hline & Centrum & & & & & & \\
\hline \multirow[t]{3}{*}{ Caudal bone } & Parhypural & & & & & & \\
\hline & Hypural bone & & & & & & \\
\hline & Epural bone & & & & & & \\
\hline \multirow{6}{*}{$\begin{array}{l}\text { Shoulder } \\
\text { girdle } \\
\text { bone }\end{array}$} & Clavicle & & & & & & \\
\hline & Postclavicle & & & & & & \\
\hline & Supraclavicle & & & & & & \\
\hline & Scapula & & & & & & \\
\hline & Actinost & & & & & & \\
\hline & Coracoid & & & & & & \\
\hline
\end{tabular}

spines were ossified (Fig. 2C). On the 16th day after hatching, post-larvae showed an average total length of $13.4 \pm$ $0.07 \mathrm{~mm}$ and an increase of 9 interneural spines. The number of interhemal spines increased to 16-18. During this period, seven ribs began to ossify. Three hypural bones ossified in coccyx (Fig. 2D).

At 24 days after hatching, post-larvae had an average total length of $15.2 \pm 0.07 \mathrm{~mm}$, and an epural bone ossified in coccyx. The parhypural bone was ossified, and two pieces of hypural bone were increased to form a total of five fragments. At this time, ossification of coccyx and pelvic girdle bone was completed with the ossification of pelvic girdle bone (Fig. 2E).

\section{3) Shoulder girdle bone}

In the shoulder girdle bone, the posttemporal is articulated to the cranium and basioccipital, and supports the pectoral fin. The development of shoulder girdle bone of $L$. obesus larvae is shown in Table 2.

Immediately after hatching, the pre-larvae had an average total length of $7.60 \pm 0.12 \mathrm{~mm}$, and the collarbone was ossified first (Fig. 3A). On the 3 day after hatching, the pre-larvae showed an average total length of $8.95 \pm 0.04$ $\mathrm{mm}$ and the upper clavicle ossified at the upper part of the 
A
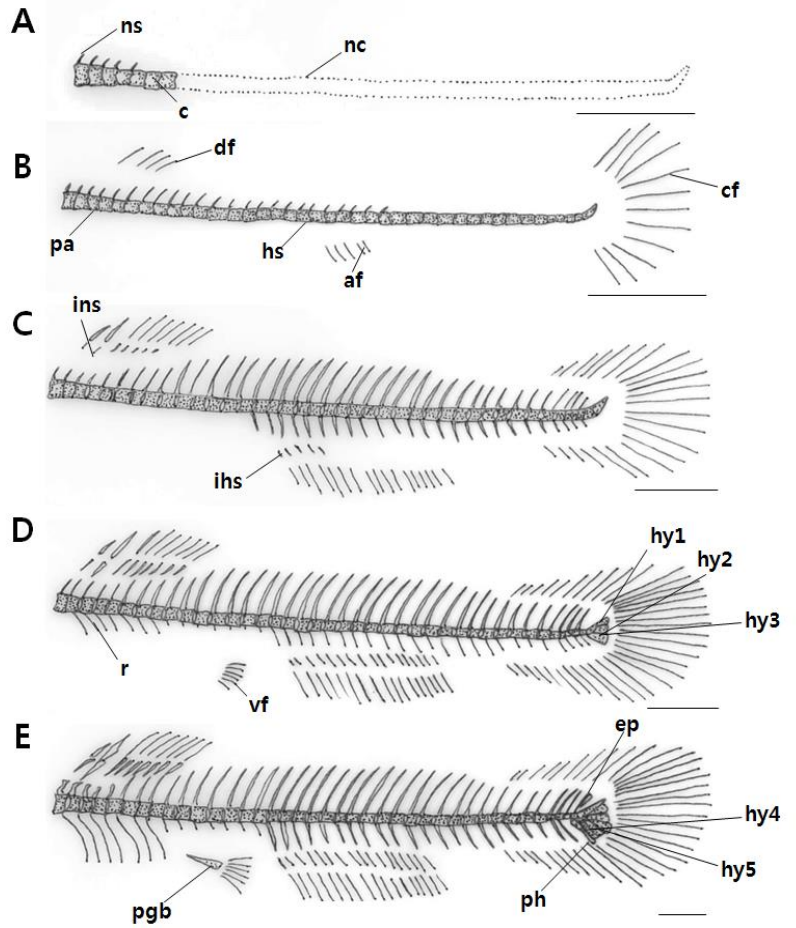

Fig. 2. Ossification of the vertebra and caudal skeleton and pelvic girdle in Liobagrus obesus. A: 7.60 $\mathrm{mm}$ in total length (TL) newly hatched larvae; $\mathrm{B}$ : $8.95 \mathrm{~mm}$ in TL 3 days after hatching; C: $9.62 \mathrm{~mm}$ in TL, 10 days after hatching; D: $13.4 \mathrm{~mm}$ in TL 16 days after hatching; E: $15.2 \mathrm{~mm}$ in TL 24 days after hatching. af, anal fin; c, centrum; cf, caudal fin; df, dorsal fin; ep, epural bone; hs, hemal spine; hy, hypural bone; ihs, interhemal spine; ins, interneural spine; ns, neural spine; nc, notocord; pa, parapophysis; ph, parhypural bone; pgb, pelvic girdle bone; $r$, rib; vf, ventral fin. Scale bars $=1.0 \mathrm{~mm}$.

clavicle. And the posterior clavicle was ossified in the lower part (Fig. 3B).

On the 10th day after hatching, pre-larvae had an average total length of $9.62 \pm 0.53 \mathrm{~mm}$, and three pectoral stems developed. (Fig. 3C). On the 16th day after hatching, an average total length was $13.4 \pm 0.07 \mathrm{~mm}$, and the scapula and two radial bones ossified. The posterior clavicle was elongated (Fig. 3D).

At 24 days after hatching, the post-larvae had an average total length of $15.2 \pm 0.07 \mathrm{~mm}$, and coracoids and four

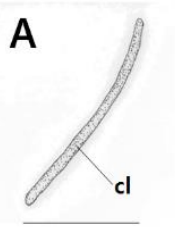

B

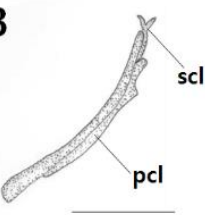

SC
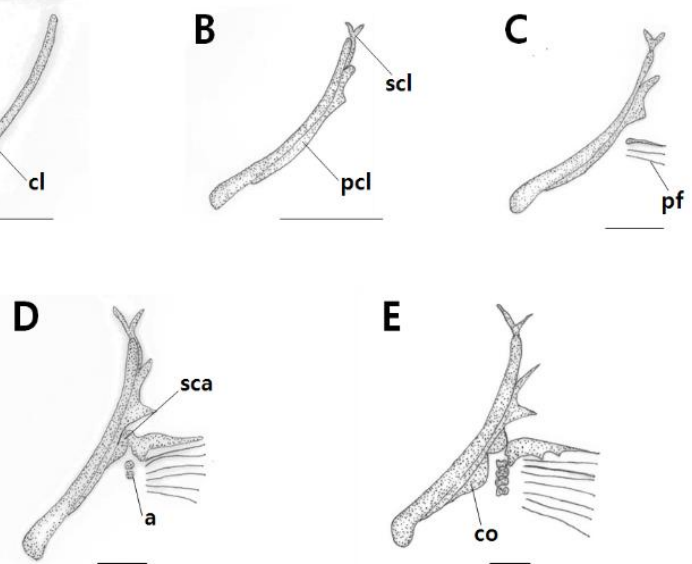

sca
Fig. 3. Ossification of the shoulder girdle bone in $\mathbf{L i}$ obagrus obesus. A: $7.60 \mathrm{~mm}$ in total length (TL) newly hatched larvae; B: $8.95 \mathrm{~mm}$ in TL 3 days after hatching; C: $9.62 \mathrm{~mm}$ in TL, 10 days after hatching; D: $13.4 \mathrm{~mm}$ in TL 16 days after hatching; E: $15.2 \mathrm{~mm}$ in TL 24 days after hatching. a, actinost; co, coracoid; cl, clavicle; pcl, postclavicle; pf, pectoral fin; sca, scapular; scl, supraclavicle. Scale bars $=0.5 \mathrm{~mm}$.

radial bones were ossified. The soft ray was increased to 9 , and the ossification of the shoulder was completed (Fig. 3E).

\section{DISCUSSION}

Interest and precise knowledge of the developmental process of the larvae in the production of fish seeding is essential for the detection and elimination of skeletal abnormalities in the early stages of breeding (Koumoundouros et al., 1997a,b). It provides a basic phylogenetic taxonomic trait of the young stage, and there is a high heat to study this field (Mook, 1977; Potthoff et al., 1988; Faustino \& Power, 1999; Liu, 2001; Sfakianakis et al., 2004). In addition, in terms of skeletal development of tibia fish larvae, the jaw bone or visceral skeleton related to food intake and respiratory function have a tendency to be predominantly ossified (Ozawa, 1976). The number of jaw teeth and pharyngeal used for food intake increases with 
the change in feeding habits (Kohno et al., 1983).

L. obesus was ossified on the first day after hatching, and maxillary and dentary functioning related to cranium parasphenoid and feeding, and clavicle supporting pectoral fin were ossified first. Compared with other fish belonging to other families, Luciogobius guttatus (Kim et al., 1992) showed that the parasphenoid, basioccipital, maxillary, dentary, articular and clavicle were ossified first on the 11 th day after hatching. Hyporhamphus sajori (Lee et al., 2001) showed the parasphenoid and clavicle were ossified immediately after hatching. Chaenogobius laevis (Kim \& Han, 1989) showed that the basioccipital and parasphenoid of cranium and maxillary of visceral skeleton were ossified at 9-10 days after hatching. The clavicle ossified on the 13th day after hatching.

On the 3 day after hatching, Gasterosteus aculeatus (Han \& Kim, 1989) showed that maxillary and dentary including exoccipital, basioccipital, and frontal were ossified. On the 19th day after hatching, the clavicle and upper clavicle were ossified. Rhinchocypris oxycephalus (Han \& Noh, 2001) showed that parasphenoid at 6 days after hatching and the clavicle ossified at 13 days after hatching.

While Lampris guttatus (Kim et al., 1992) and H. sajori (Lee et al., 2001) as well as L. obesus showed simultaneous ossification of parasphenoid, jaw bone, and clavicle, the Chysis laevis (Kim \& Han, 1989), Gasterosteus aculeatus (Han \& Kim, 1989) and R. oxycephalus (Han \& Noh, 2001) showed that parasphenoid and jaw bone first began to ossify followed by the clavicle. This showed a difference in skeletal development pattern. However, in all of these species, the jaw bone constituting the jaw is first ossified, suggesting that the cranium is an important element for feeding and respiration, and is the site where ossification occurs preferentially (Vandewalle et al., 1997). At the same time, the clavicle supporting the sternohyoideus muscle plays an important role in the mouth opening and function of feeding (Wagemans \& Vandewalle, 1999).

According to the shape development at the larvae stage, the development of the internal skeleton, especially the formation of thorns at the craniofacial skeleton, varies depending on the developmental condition and environment, but thorns formed in the parietal region, operculum, orbit, and shoulder girdle are important traits (Okiyama, 1988). L. obesus has one spinous ray in the pectoral fin of the shoulder girdle, very sharp and hard, with three to five small thorns. The same Amblycipitidae fish, L. mediadiposalis (Choi et al., 2008), has four to six thorns on the pectoral spinous ray. L. andersoni has one to three thorns, which is an important trait to distinguish these three species. Meanwhile, the shape of the body is similar to each other at the young fish stage, and the number and timing of thorns formed on the spinous ray of pectoral fin differs from species to species, which can lead to confusion in classification. On the 24th day after hatching, L. obesus showed that two thorns of the spinous ray of pectoral fin were formed for the first time at an average total length of $15.3 \mathrm{~mm}$. L. mediadiposalis showed that two to three thorns were formed at an average total length of $16.3 \mathrm{~mm}$ on the $35^{\text {th }}$ day after hatching, and the number of thorns is similar, but L. mediadiposalis (Choi et al., 2008) was found to have one more than L. obesus In addition, the formation timing for L. mediadiposalis (Choi et al., 2008) was later than L. obesus.

Among the skeletons that support the pectoral fins, a rather large foramen is formed in the scapula, which is considered to be a typical trait that occurs mainly in sea anemone fish (Koumoundouros et al., 2001). On the 24th day after hatching to the juvenile, and when the average length was $15.3 \mathrm{~mm}$, the ossification of the shoulder girdle of $L$. obesus is complete, and no holes were formed in the scapula in this period. Spotted sea bass, Lateolabrax maculatus (Kang et al., 2012) showed that holes were formed in the scapula and osteochondral bone, but the holes formed in the osteochondral bone especially disappeared as it grew. Based on the fact that these are formed in many Scorpaeniformes fishes (Kim et al., 1997; Han et al., 2001), includ- 
ing many perciformes fishes such as Dentex tumifrons (Koumoundouros et al., 2001), and damsel fishes (Emery, 1973), it is likely that it is a common trait of fish. L. obesus differs from other fish in that there is no hole formed in the scapula. To confirm whether or not the typical traits in Amblycipitidae fish are judged, it is necessary to carry out research on the development of larvae skeleton of L. mediadiposalis and L. andersoni.

In terms of the vertebra ossification of $L$. obesus larvae, seven centrums were ossified in abdominal vertebrae with an average total length of $7.92 \mathrm{~mm}$. The ossification progressed from the abdominal vertebrae to the caudal vertebrae. After that, at the same time as the ossification of the centrum was completed, the ossification of the tibia was completed. C. laevis (Kim \& Han, 1989) showed that the caudal peduncle was ossified after the ossification of the centrum was complete. As for L. guttatus (Kim et al., 1992), H. sajori (Lee et al., 2001), R. oxycephalus (Han \& Noh, 2001), Pungtungia herzi (Lee et al., 2002), Pseudopungtungia nigra (Lee, 2004) before the ossification of the centrum was completed, the caudal peduncle was ossified, showing a difference.

Thus, in the skeletal formation of fish, ossification is controlled by their lifestyle, and the difference in lifestyle leads to changes in the degree and order of ossification, which can make various changes in skeletal development of larvae (Mook, 1977). In addition, studies on skeleton can be used as useful data in ecology as well as species identification. It is also said that it is useful to understand the skeletal structure of fishes and to get systematic estimation, and so therefore, it is necessary to continue research on skeletal development in the future.

\section{REFERENCES}

Choi NH, Seo WI, Kim CC, Park CK, Heo SJ, Yoon SM, Han KH, Lee WK (2008) Spawning behavior and early life history of the Liobagrus mediadiposalis in the Ko- rean endemic species. J Korean Fish Soc 41:478-484.

Emery AR (1973) Ecology and functional osteology damselfish (Pisces; Pomacentridae) at Alligator Reef, Florida Keys. Bull Mar Sci 23:649-770.

Faustino M, Power DM (1999) Development of the pectoral, pelvic, dorsal and anal fins in cultured sea bream. J Fish Biol 54:1094-1110.

Fukuhara O (1992) Study on the development of functional morphology and behavior of the larvae of eight commercially valuable teleost fishes. Contr Fish Res Jpn Sea Block 25:1-113.

Han KH, Kim YU (1989) Spawning behavior, embryonic development, and morphology of larvae and juveniles of three spined sickleback, Gasterosteus aculeatus aculeatus (Linnaeus) reared in the laboratory. Bull Nat Fish Univ Pusan 29:11-36.

Han KH, Lim SK, Kim KS, Kim CW, Yoo DJ (2001) Osteological development of the larvae and juveniles of Sebastiscus tertius (Barsukov et Chen) in Korea. Korean J Ichthyol 13:63-68.

Han KH, Noh BY (2001) Osteological development of larvae and juveniles of Rhynchocypris oxycephalus (Teleostei: Cyprinidae). Bull Yosu Nat Univ 16:369377.

Kang CB, Myoung JG, Kim YU, Kim HC (2012) Early osteological development and squamation in the spotted sea bass Lateolabrax maculates (Pisces: Lateolabracidae). Kor J Fish Aquat Sci 45:271-282.

Kawamura K, Hosoya K (1991) A moidifed double staining techinque marking a transparent fish skeletal. Bull Nat Res Inst Aquaculture 20:11-18.

Kim HS, Yang H, Hong YK (2012) Spawning site characters in the natural environment of bull-head torrent catfish, Ligbagrus obesus (Siluriformes: Amblycipitidae) in the Gosan stream, Mangyeong river water system, Korea. Korean J Ichthyol 24:183-190.

Kim IS, Choi Y, Lee CL, Lee YJ, Kim BJ, Kim JH (2005) Illustrated Book of Korean Fishes. Kyo-Hak publish- 
ing, Seoul Korea, pp 146-147.

Kim YU, Han KH (1989) Early life history of the marine animals 1. Egg development, larvae and juveniles of Chaenogobius laevis (Steindachner). Korean J Fish Aquat Sci 22:317-331.

Kim YU, Han KH, Kang CB, Kim JK, Byun SK (1997) The early life history of the rockfish, Sebastiscus marmoratus 2. Morphology and skeletal development of larvae and juvenile. Korean J Ichthyol 9:186-194.

Kim YU, Han KH, Kang CB, Ryu JH (1992) Early life history and spawning behavior of the gobiid fish, Luciogobius guttatus Gill. Korean J Ichthyol 4:1-13.

Kohno H, Taki Y, Ogasawara Y, Shirojo Y, Taketomi M, Inoue M (1983) Development of swimming and feeding function in larval Pagrus major. Japan J Ichthyol 30:47-60.

Koumoundouros G, Divanach P, Kentouri M (1999) Osteological development of the vertebral column and of the caudal complex in Dentex dentex. J Fish Bio 54: 424-436.

Koumoundouros G, Divanach P, Kentouri M (2001) Osteological development of Dentex dentex (Osteichthyes: Sparidae): dorsal, anal, paired fins and squamation. Mar Bio 138:399-406.

Koumoundouros G, Gagliardi F, Divanach P, Boglione C, Cataudella S, Kentouri M (1997a) Normal and abnormal osteological development of caudal fin in Sparus aurata L fry. Aquaculture 149:215-226.

Koumoundouros G, Oran G, Divanach P, Stefanakis S, Kentouri M (1997b) The opercular complex deformity in intensive gilthead sea bream (Spartus aurata L.) larviculture. Moment of apparition and description. Aquaculture 156:165-177.

Lee SH (2004) Early development and reproductive ecology of Pseudopungtungia nigra in Korea. Dep Fish Sci Yosu Nat Univ pp 88-98.

Lee SH, Han KH, Hwang DS (2002) The early life history and spawning behavior of Pungtungia herzi. Dep Fish
Sci Yosu Nat Univ pp 115-126.

Lee SJ, Kim YU, Han KH (2001) Osteological development of larvae and juveniles of Hyporhamphus sajori (Teleostei: Hemiramphidae). Korean J Ichthyol 13: 173-180.

Liu CH (2001) Early osteological development of the yellow tail Seriola dumerili (Pisces: Carangidae). Zool Stud 40:289-298.

Mook D (1977) Larval and osteological development of the sheepshead, Archosargus probatocephalus (Pisces: Sparidae). Copeia 1977:126-133.

NBC (National Biodiversity Center) (2018) https://species. nibr.go.kr/home/mainHome.do?cont_link=009\&subMe $\mathrm{nu}=009002 \& \operatorname{contCd}=009002 \& \mathrm{ktsn}=120000057680$.

Retrieved January 11, 2018.

Okiyama M (1988) An Atlas of the Early State Fishes in Japan. Tokai Univ Press p 1160.

Ozawa T (1976) Early life history of the gonostiomatid fish, Polichthys mauli, in the ocean region of southern Japan. Jap J Ichthyol 23:43-54.

Park IS, Seol DW, Kang EJ, Kim CH (2006) Morphometric characteristics of torrent catfish (Amblycipitidae) in Korea. Korean J Ichthyol 18:209-215.

Park JY, Hong CG, Cho JK, Son MH, Han KH, Park JM (2015) Early osteological development of the larvae and juveniles in sevenband grouper. Epinephelus septemfasciatus (Pisces: Serranidae). Korean J Ichthyol 27:189-198.

Potthoff T, Kelley S, Collins LA (1988) Osteological development of the red snapper, Lutjanu scampechanus (Lutjanidae). Bull Mar Sci 43:1-40.

Seo WI, Han KH, Yoon SM, Kim CC, Hwang SY, Lee SH, Lee CL, Son YM, Kim IS (2006) Early life history of the Liobagrus obesus (Pisces, Amblycipitidae). Dev Reprod 10:41-45.

Sfakianakis DG, Koumoundouros G, Divanach P, Kentouri M (2004) Osteological development of the vertebral column and of the fins in Pagellus erythrinus (L. 1758). 
Temperature effedt on the developmental plasticity and morpho-anatomical abnormalities. Aquaculture 232: 407-424.

Son YM, Byeon HK (2004) Feeding habits of bull-head torrent catfish, Liobagrus obesus from the Geum River, Korea. Korean J Ichthyol 16:336-340.

Son YM, Lee JH (1989) Karyotypes of genus Liobagrus (Pisces: Amblycipitidae) in Korea. Korean J Ichthyol 1:64-72.

Vandewalle P, Gluckmann I, Baras E, Huriaux F, Focant B
(1997) Postembryonic development of the cephalic region in Heterobranchus longifilis. J Fish Bio 50:227253.

Wagemans F, Vandewalle P (1999) Development of the cartilaginous skull in Solea solea: trends on Pleuronectiforms. Ann Sci Nat 20:39-52.

Yoon HN, Kim JM, Bae YS, Chae BS (2007) Feeding habits of Korean torrent catfish, Liobagrus andersoni in a tributary of the namhan river, Korea. Korean J Ichthyol 19:236-245. 